\title{
Inflammation and Cognition in Children and Adolescents: A Call for Action
}

\author{
Mireia Adelantado-Renau*, Maria Reyes Beltran-Valls and Diego Moliner-Urdiales \\ LIFE Research Group, University Jaume I, Castellon, Spain
}

Keywords: inflammatory factors, cognitive function, health, childhood, adolescence

\section{INTRODUCTION}

Inflammation is a natural response to injury or infection, which promotes tissue survival, remodeling, and repair, as well as adaptation to stress and restoration of the homeostatic state (1). In the acute phase of an inflammatory response, which could persist for a few days, inflammatory factors such as cytokines/chemokines, immune-related effectors, acute phase proteins, and reactive oxygen and nitrogen species are released, thereby triggering coordinated biological events (1). However, a prolonged inflammatory response, also known as chronic low-grade inflammation (1), may contribute to the pathogenesis of several cardiovascular and metabolic diseases (e.g., atherosclerosis, diabetes, and cancer) $(2,3)$ as well as to the development of neuropsychiatric disorders and cognitive dysfunctions (4).

\section{OPEN ACCESS}

Edited by:

Hanna E. Stevens,

The University of lowa, United States

Reviewed by:

Antonio Lucio Teixeira,

University of Texas Health Science Center at Houston, United States Serena Gumusoglu,

The University of lowa, United States

${ }^{*}$ Correspondence:

Mireia Adelantado-Renau adelantm@uji.es

Specialty section:

This article was submitted to Child and Adolescent Psychiatry,

a section of the journal

Frontiers in Pediatrics

Received: 24 April 2020

Accepted: 07 August 2020

Published: 09 September 2020

Citation:

Adelantado-Renau M

Beltran-Valls MR and

Moliner-Urdiales D (2020)

Inflammation and Cognition in

Children and Adolescents: A Call for

Action. Front. Pediatr. 8:583

doi: 10.3389/fped.2020.00583
Cognition involves a set of mental processes that shape perception, memory, intellect, and action, including executive functions (e.g., cognitive inhibition, cognitive flexibility, and working memory), and other cognitive domains (e.g., verbal fluency and comprehension) (5). Although it has been suggested that the immune system might modulate brain functioning, how inflammatory factors could influence cognition is poorly understood. Here, we provide context and three open questions that need to be answered to move the field forward.

\section{Is Low-Grade Systemic Inflammation Associated With Cognition in Children and Adolescents?}

The current understanding of the association between systemic inflammation, which takes place outside the central nervous system, and cognition has been mainly focused on the two endpoints of the human life span as well as on psychiatric patients. In extremely preterm infants, incremented levels of inflammatory proteins (e.g., C-reactive protein) have been related to impaired cognitive function later in life $(6,7)$. Interestingly, prenatal inflammation, measured by interleukin-6, has also been shown to have an impact on postnatal cognitive outcomes (8). In older adults, there is a link between incremented levels of proinflammatory cytokines (e.g., interleukin-6, interleukin-1 $\beta$, and tumor necrosis factor- $\alpha$ ) and neurodegenerative disorders, such as Alzheimer's disease and other dementias (9). In psychiatric patients, a growing body of evidence has shown that high levels of proinflammatory cytokines and C-reactive protein are associated with altered cognition in individuals with neuropsychiatric disorders, such as schizophrenia, bipolar disorder, and major depressive disorders (10). Additionally, prior literature has pointed out that a state of chronic low-grade systemic inflammation could also negatively influence cognition in healthy midlife adults (11).

In contrast to this prior evidence, the association between inflammation and cognition, both assessed during childhood and adolescence (4-18 years), is poorly understood since only six studies have been conducted in this age group, showing inconclusive results (12-17). Concurring with research in other age range populations, four studies have shown that elevated levels of circulating 
inflammatory factors in children and adolescents are associated with impaired cognitive processes $(12-14,16)$. Conversely, two studies reported null associations between these parameters (15, 17). This previous research focused on only some immunerelated effectors, cytokines, and C-reactive protein. With regard to cognition, studies have mainly investigated memory $(12,15-$ 17) and a global measure of executive function (12, 14-16), with only a few studies examining other cognitive domains, such as cognitive inhibition $(16,17)$, cognitive flexibility (17), or attention (14). The paucity of studies and the methodological differences among them (e.g., selected signaling proteins and cognitive-related outcomes, and study design) prevent drawing firm conclusions and make necessary additional research on this interesting and promising area.

During childhood and adolescence, brain regions are continuously developing (18), which shapes the cognitive domains. Indeed, these periods of life provide a developmental window with a great opportunity to experience structural and functional organization of the brain influenced by exogenous and endogenous factors (19), for example, inflammation. Therefore, future studies analyzing the impact of a wide range of inflammatory factors on the whole range of cognitive outcomes in children and adolescents are needed to advance our understanding of this Research Topic.

\section{How Could Inflammation Influence Complex Higher-Order Neurological Functions?}

Inflammatory factors could influence cognition through two different routes. Firstly, systemic inflammatory proteins can enter the brain by crossing the blood-brain barrier via active transport mechanisms or via vagal nerve stimulation (20). Secondly, within the brain, inflammatory factors can be expressed by astroglia, microglia, neurons, and endothelial cells as a consequence of brain injury, trauma, or intracerebral infections (21). In animal models, both systemic and central inflammation may alter cognition through its effects on synaptic plasticity, neurotransmission, and dendritic branching (22). In humans, clinical research has suggested that systemic inflammatory agents may play a substantial role in neurodevelopmental processes, such as synaptic plasticity, neurogenesis, and neuromodulation (21). Therefore, we speculate that inflammation alters these brain functions, which ultimately leads to alterations in cognitive functioning. The impact of inflammation on cognition could be indirectly related to several cardiometabolic disorders (e.g., obesity, type 2 diabetes, and hypertension), since the pathogenesis of these disorders is closely linked to chronic low-grade systemic inflammation $(2,3)$. However, the exact molecular and cellular pathways by which inflammatory factors may influence cognition remain to be elucidated. It is likely that inflammatory agents exert unique effects in different cortical regions and may have specific consequences on the brain regions depending on the state of brain development (23). Previous studies in humans, which included brain imaging data, have suggested that peripheral proinflammatory cytokines, such as interleukin-6, interleukin-1 $\beta$, and tumor necrosis factor- $\alpha$, are associated with changes in functional connectivity as well as in cortical thickness and surface area in specific regions of the brain $(23,24)$. In this sense, further longitudinal studies including brain imaging data, which could detect brain function and structural adaptations, may contribute to a better understanding of the effect of inflammation on cognition over a period of time. In addition, further studies could also analyze brain functions as mediator mechanisms involved in the association between inflammation and cognition.

\section{How Could Inflammation Be Modulated to Improve Cognition?}

Therapeutic or prophylactic immunomodulation is a strategy that activates the non-specific immune system to counteract inflammation (25). Alternatively, prior evidence has suggested that lifestyle behaviors, such as diet, physical activity, or sleep, could act as preventive strategies influencing the inflammatory levels, since associations between these behaviors and inflammation have been reported in children and adolescents $(26,27)$. For instance, physical activity affects inflammatory mediators by the reduction of visceral fat mass, improvement of endothelial function and insulin sensitivity, and elevation of antiinflammatory cytokines levels and other muscle contractionderived proteins (28).

Considering that childhood and adolescence are crucial periods of life in terms of establishing healthy lifestyle behaviors and acquisition of cognitive skills, the investigation of the influence of these modifiable behaviors on inflammation and cognitive functioning is of paramount importance. Therefore, from a public health perspective, further prospective cohort studies and non-pharmacological randomized lifestyle interventions focusing on inflammation as a primary outcome could help to predict the direction of causality and to understand its role in cognition in youths. In addition, since the mechanisms underlying these associations have not been clearly identified, we believe that inflammatory-mediated pathways in relation to cognition should be considered as a new and exciting Research Topic.

\section{CONCLUSION}

Since high levels of inflammatory factors during childhood and adolescence, considered important periods of life in terms of brain development, seem to track into adulthood (29), the promotion of health is particularly needed. Thus, further research is warranted to not only facilitate our understanding of neural-immune communication pathways and cytokinemediated pathophysiological processes but also to design efficient non-pharmacological lifestyle intervention programs to tackle inflammation-related diseases. These lifestyle interventions may be cost-effective, overcoming the benefits of pharmacological approaches (e.g., anti-inflammatory drugs, immunomodulators, or nutraceuticals), since they may exert multi-systemic positive effects on health with little contraindications and at a lower cost. Moreover, lifestyle interventions could be used not only as 
treatment strategies but also as primary prevention strategies. Future studies should consider participants' maturational status to account for individual developmental features. In addition, studies should include sample sizes large enough to provide significant statistical power as well as guarantee participants' compliance. Specifically, lifestyle interventions focused on physical activity should precisely define its dose in terms of intensity, type, and duration in order to facilitate comparisons among studies. With regard to diet, interventions should focus not only on dietary patterns but also on the intake of specific foods, nutrients, and non-nutrient food components. Lastly, sleep interventions aimed at modulating inflammation through the improvement of sleep patterns should also be considered.

Based on previous scientific literature, low-grade systemic inflammatory proteins could be identified as critical factors for cognitive functioning during youth. We believe that the scientific community should be aware of the gap highlighted in this

\section{REFERENCES}

1. Medzhitov R. Origin and physiological roles of inflammation. Nature. (2008) 454:428-35. doi: 10.1038/nature07201

2. Hotamisligil GS. Inflammation and metabolic disorders. Nature. (2006) 444:860-7. doi: 10.1038 /nature05485

3. Libby P. Inflammation and cardiovascular disease mechanisms. Am J Clin Nutr. (2006) 83:456S-60S. doi: 10.1093/ajcn/83.2.456S

4. Borsini A, Zunszain PA, Thuret S, Pariante CM. The role of inflammatory cytokines as key modulators of neurogenesis. Trends Neurosci. (2015) 38:14557. doi: 10.1016/j.tins.2014.12.006

5. Donnelly JE, Hillman CH, Castelli DM, Etnier JL, Lee S, Tomporowski P, et al. Physical activity, fitness, cognitive function, and academic achievement in children: a systematic review. Med Sci Sports Exerc. (2016) 48:1197222. doi: 10.1249/MSS.0000000000000901

6. Rose J, Vassar R, Cahill-Rowley K, Hintz SR, Stevenson DK. Neonatal biomarkers of inflammation: correlates of early neurodevelopment and gait in very-low-birth-weight preterm children. Am J Perinatol. (2015) 33:718. doi: 10.1055/s-0035-1557106

7. Kuban KCK, Joseph RM, O’Shea TM, Heeren T, Fichorova RN, Douglass L, et al. Circulating inflammatory-associated proteins in the first month of life and cognitive impairment at age 10 years in children born extremely preterm. J Pediatr. (2017) 180:116-23. doi: 10.1016/j.jpeds.2016.09.054

8. Rudolph MD, Graham AM, Feczko E, Miranda-Dominguez O, Rasmussen JM, Nardos R, et al. Maternal IL-6 during pregnancy can be estimated from newborn brain connectivity and predicts future working memory in offspring. Nat Neurosci. (2018) 21:765-72. doi: 10.1038/s41593-018-0128-y

9. Sartori AC, Vance DE, Slater LZ, Crowe M. The impact of inflammation on cognitive function in older adults: implications for healthcare practice and research. J Neurosci Nurs. (2012) 44:206-17. doi: 10.1097/JNN.0b013e3182527690

10. Misiak B, Stańczykiewicz B, Kotowicz K, Rybakowski JK, Samochowiec J, Frydecka D. Cytokines and C-reactive protein alterations with respect to cognitive impairment in schizophrenia and bipolar disorder: a systematic review. Schizophr Res. (2018) 192:16-29. doi: 10.1016/j.schres.2017.04.015

11. Marsland AL, Gianaros PJ, Kuan DCH, Sheu LK, Krajina K, Manuck SB. Brain morphology links systemic inflammation to cognitive function in midlife adults. Brain Behav Immun. (2015) 48:195-204. doi: 10.1016/j.bbi.2015.03.015

12. Kyriklaki A, Margetaki K, Kampouri M, Koutra K, Bitsios P, Chalkiadaki G, et al. Association between high levels of inflammatory markers and cognitive outcomes at 4 years of age: the Rhea mother-child cohort study, Crete, Greece. Cytokine. (2019) 117:1-7. doi: 10.1016/j.cyto.2019.01.010

13. Lee SE, West KP, Cole RN, Schulze KJ, Wu LS-F, Yager JD, et al. General intelligence is associated with subclinical inflammation in Nepalese children: manuscript in order to take action and expand the knowledge on inflammation and cognition in the young population.

\section{AUTHOR CONTRIBUTIONS}

MA-R was involved in the manuscript preparation and drafting of the initial manuscript. MRB-V and DM- $U$ were involved in the manuscript preparation and critical revision. All authors contributed to the article and approved the submitted version.

\section{FUNDING}

The DADOS Study was funded by the Spanish Ministry of Economy and Competitiveness, MINECO (DEP2013-45515-R), and the Jaume I University of Castellon, UJI (P1·1A2015-05 and UJI-A2019-12). This work was partly supported by a Sunny Sport research grant from the Schweppes Suntory Spain Company. a population-based plasma proteomics study. Brain Behav Immun. (2016) 56:253-63. doi: 10.1016/j.bbi.2016.03.023

14. Huang Y-S, Guilleminault C, Hwang F-M, Cheng C, Lin C-H, Li H-Y, et al. Inflammatory cytokines in pediatric obstructive sleep apnea. Medicine. (2016) 95:e4944. doi: 10.1097/MD.0000000000004944

15. Jonker I, Klein HC, Duivis HE, Yolken RH, Rosmalen JGM, Schoevers RA. Association between exposure to HSV1 and cognitive functioning in a general population of adolescents. The TRAILS Study. PLoS ONE. (2014) 9:e101549. doi: 10.1371/journal.pone.0101549

16. Cullen AE, Tappin BM, Zunszain PA, Dickson H, Roberts RE, Nikkheslat N, et al. The relationship between salivary $\mathrm{C}$-reactive protein and cognitive function in children aged 11-14 years: does psychopathology have a moderating effect? Brain Behav Immun. (2017) 66:221-9. doi: 10.1016/j.bbi.2017.07.002

17. Adelantado-Renau M, Esteban-Cornejo I, Rodriguez-Ayllon M, CadenasSanchez C, Gil-Cosano JJ, Mora-Gonzalez J, et al. Inflammatory biomarkers and brain health indicators in children with overweight and obesity: the ActiveBrains project. Brain Behav Immun. (2019) 81:588-97. doi: 10.1016/j.bbi.2019.07.020

18. Gogtay N, Giedd JN, Lusk L, Hayashi KM, Greenstein D, Vaituzis AC, et al. Dynamic mapping of human cortical development during childhood through early adulthood. Proc Natl Acad Sci USA. (2004) 101:81749. doi: 10.1073/pnas.0402680101

19. van Praag H, Kempermann G, Gage FH. Neural consequences of enviromental enrichment. Nat Rev Neurosci. (2000) 1:1918. doi: $10.1038 / 35044558$

20. Banks WA, Lynch JL, Price TO. Cytokines and the Blood-Brain Barrier. In: Siegel, A, Zalcman SS, editors. The Neuroimmunological Basis of Behavior and Mental Disorders. Boston, MA: Springer (2009). p. 317. doi: 10.1007/978-0-387-84851-8_1

21. McAfoose J, Baune BT. Evidence for a cytokine model of cognitive function. Neurosci Biobehav Rev. (2009) 33:35566. doi: 10.1016/j.neubiorev.2008.10.005

22. Yirmiya R, Goshen I. Immune modulation of learning, memory, neural plasticity and neurogenesis. Brain Behav Immun. (2011) 25:181-213. doi: 10.1016/j.bbi.2010.10.015

23. Prats-Soteras X, Jurado MA, Ottino-González J, García-García I, Segura B, Caldú $\mathrm{X}$, et al. Inflammatory agents partially explain associations between cortical thickness, surface area, and body mass in adolescents and young adulthood. Int J Obes. (2020) 44:1487-96. doi: 10.1038/s41366-020-0582-y

24. Marsland AL, Kuan DC-H, Sheu LK, Krajina K, Kraynak ET, Manuck SB, et al. Systemic inflammation and resting state connectivity of the default mode network. Anal Chem. (2017) 25:368-79. doi: 10.1016/j.bbi.2017.01.013

25. Norton EB, Clements JD, Voss TG, Cárdenas-Freytag L. Prophylactic administration of bacterially derived immunomodulators improves the 
outcome of influenza virus infection in a murine model. J Virol. (2010) 84:2983-95. doi: 10.1128/JVI.01805-09

26. Arouca A, Michels N, Moreno LA, González-Gil EM, Marcos A, Gómez S, et al. Associations between a Mediterranean diet pattern and inflammatory biomarkers in European adolescents. Eur J Nutr. (2018) 57:1747-60. doi: 10.1007/s00394-017-1457-4

27. Pérez de Heredia F, Garaulet M, Gómez-Martínez S, Díaz LE, Wärnberg J, Androutsos O, et al. Self-reported sleep duration, white blood cell counts and cytokine profiles in European adolescents: the HELENA study. Sleep Med. (2014) 15:1251-8. doi: 10.1016/j.sleep.2014.0 4.010

28. Han Y, Liu Y, Zhao Z, Zhen S, Chen J, Ding N, et al. Does physical activity-based intervention improve systemic proinflammatory cytokine levels in overweight or obese children and adolescents? Insights from a meta-Analysis of randomized control trials. Obes Facts. (2019) 12:65368. doi: 10.1159/000501970
29. Juonala M, Viikari JSA, Rönnemaa T, Taittonen L, Marniemi J, Raitakari OT. Childhood C-reactive protein in predicting CRP and carotid intimamedia thickness in adulthood. Arterioscler Thromb Vasc Biol. (2006) 26:18838. doi: 10.1161/01.ATV.0000228818.11968.7a

Conflict of Interest: The authors declare that the research was conducted in the absence of any commercial or financial relationships that could be construed as a potential conflict of interest.

Copyright (c) 2020 Adelantado-Renau, Beltran-Valls and Moliner-Urdiales. This is an open-access article distributed under the terms of the Creative Commons Attribution License (CC BY). The use, distribution or reproduction in other forums is permitted, provided the original author(s) and the copyright owner(s) are credited and that the original publication in this journal is cited, in accordance with accepted academic practice. No use, distribution or reproduction is permitted which does not comply with these terms. 